\title{
Electrocardiographic abnormalities among Mexican Americans: Correlations with diabetes, obesity, and the metabolic syndrome
}

\author{
Saulette R. Queen ${ }^{1}$, Beverly Smulevitz ${ }^{1}$, Anne R. Rentfro ${ }^{2}$, Kristina P. Vatcheva ${ }^{3}$, \\ David D. McPherson ${ }^{1}$, Susan P. Fisher-Hoch ${ }^{3}$, Joseph B. McCormick ${ }^{3}$, Susan T. Laing ${ }^{{ }^{*}}$ \\ ${ }^{1}$ Division of Cardiology, Department of Internal Medicine, University of Texas Health Science Center-Houston, Houston, USA \\ ${ }^{2}$ College of Nursing, University of Texas at Brownsville, Brownsville, USA \\ ${ }^{3}$ Division of Epidemiology, Human Genetics and Environmental Health, University of Texas School of Public Health, Brownsville \\ Campus, Brownsville, USA \\ Email: Susan.T.Laing@uth.tmc.edu
}

Received 28 January 2012; revised 2 March 2012; accepted 12 March 2012

\section{ABSTRACT}

INTRODUCTION: Resting ischemic electrocardiographic abnormalities have been associated with cardiovascular mortality. Simple markers of abnormal autonomic tone have also been associated with diabetes, obesity, and the metabolic syndrome in some populations. Data on these electrocardiographic abnormalities and correlations with coronary risk factors are lacking among Mexican Americans wherein these conditions are prevalent. This study aimed to evaluate the prevalent resting electrocardiographic abnormalities among community-dwelling Mexican Americans, and to correlate these findings with coronary risk factors, particularly diabetes, obesity, and the metabolic syndrome. METHODS: Study subjects $(n=1280)$ were drawn from the Cameron County Hispanic Cohort comprised of community-dwelling Mexican Americans living in Brownsville, Texas at the United States-Mexico border. Ischemic electrocardiographic abnormalities were defined as presence of ST/T wave abnormalities suggestive of ischemia, abnormal $Q$ waves, and left bundle branch block. Parameters that reflect autonomic tone, such as heart rate-corrected $Q T$ interval and resting heart rate, were also measured. RESULTS: Ischemic electrocardiographic abnormalities were more prevalent among older persons and those with hypertension, diabetes, obesity, and the metabolic syndrome. Subjects in the highest quartiles of QTc interval and resting heart rate were also more likely to have diabetes, hypertension, obesity, or the metabolic syndrome. CONCLUSIONS: Among Mexican Americans, persons with diabetes, obesity, and the metabolic syndrome were more likely to have ischemic electrocardiographic

*Corresponding author. abnormalities, longer QTc intervals, and higher resting heart rates. A resting electrocardiogram can play a complementary role in the comprehensive evaluation of cardiovascular risk in this minority population.

Keywords: Electrocardiogram; Minority; Mexican American; Coronary Risk Factors; Diabetes Mellitus; Obesity; Metabolic Syndrome; Health Disparity

\section{INTRODUCTION}

Resting electrocardiographic (EKG) abnormalities have been associated with increased cardiovascular mortality [1]. Parameters that reflect abnormal autonomic tone, such as prolonged heart rate (HR)-corrected QT (QTc) interval and elevated resting $\mathrm{HR}$, also have prognostic implications [2,3], and can easily be ascertained from a resting EKG. Prolonged QTc and elevated resting HR have been associated with diabetes, obesity, and the metabolic syndrome in some populations $[4,5]$. However, there are few published studies that evaluate resting EKG abnormalities in non-white populations, particularly the Hispanic population, wherein these conditions are highly prevalent. Mexican Americans have been shown to have a very high prevalence of diabetes, obesity, hypertension, and the metabolic syndrome [6], and yet there is a paucity of data regarding EKG abnormalities and correlations of EKG findings with coronary risk factors in this group. The United States (US) Hispanic population has almost doubled between 1990 and 2007 (9\% to 15\%) [7], and is projected to reach $30 \%$ by the year 2050 . Of the Hispanics residing in the US, Mexican Americans represent the largest and ethnically distinct subgroup. This study aimed to evaluate the prevalent resting EKG ab- 
normalities among community-dwelling Mexican Americans, and to correlate these findings with coronary risk factors, particularly diabetes, obesity, and the metabolic syndrome.

\section{METHODS}

\subsection{Study Population}

This study was approved by the Institutional Review Board of the University of Texas Health Science CenterHouston. Study subjects were drawn from the Cameron County Hispanic Cohort (CCHC) $(n=1280)$, recruited from randomly selected city blocks according to the 2000 Census as described previously [8]. The CCHC is a homogenous community-dwelling Mexican American cohort living in Brownsville (Cameron County), Texas, a city near the mouth of the Rio Grande River at the USMexico border.

Extensive family, socioeconomic, educational and personal medical histories were obtained using a directed questionnaire. Participants were asked to fast for at least 10 hours overnight before a clinic visit at the Clinical Research Unit. Anthropometric measurements obtained included height, weight, and waist circumference. The average of 3 blood pressure (BP) and HR readings taken 5 minutes apart were used. Laboratory studies performed included fasting lipid panel, hemoglobin $(\mathrm{Hb}) \mathrm{A} 1 \mathrm{c}$, fasting glucose, and high sensitivity C-reactive protein (CRP). CRP levels $>10 \mathrm{mg} / \mathrm{L}$ were excluded from analysis as such high levels likely represent acute illness [9].

The presence of hypertension was both self-reported and measured as described above. The subject was deemed to be hypertensive if the mean systolic blood pressure (SBP) was $\geq 140 \mathrm{mmHg}$ or the mean diastolic blood pressure (DBP) was $\geq 90 \mathrm{mmHg}$. Classification of diabetes was also both self-reported and based on measurement of $\mathrm{HbA} 1 \mathrm{c}(\mathrm{HbA} 1 \mathrm{c}>6.5)$ as per the latest guidelines from the American Diabetes Association [10]. Smoking status was defined as an affirmative answer to the question "Have you ever smoked $>100$ cigarettes in your life?" Body mass index (BMI) was categorized according to the National Heart Lung and Blood Institute (NHLBI) criteria. Metabolic syndrome was defined according to the criteria used by the American Heart Association and NHLBI as the presence of at least 3 of the following: 1) increased waist circumference ( $\geq 102 \mathrm{~cm}$ in males and $\geq 88 \mathrm{~cm}$ in females), 2) elevated triglyceride levels $(\geq 150 \mathrm{mg} / \mathrm{dL}), 3)$ low high density lipoprotein cholesterol (HDL-C) $(<40 \mathrm{mg} / \mathrm{dL}$ in males and $<50$ $\mathrm{mg} / \mathrm{dL}$ in females), 4) elevated blood pressure $(\geq 130 / 85$ $\mathrm{mmHg})$, and 5) elevated fasting glucose $(\geq 100 \mathrm{mg} / \mathrm{dL})$.

\subsection{EKG Analysis}

A resting 12-lead standard supine EKG (Nihon Kohden
ECG-9320, Nihon Kohden Corp., Foothill Ranch, CA) was performed. All EKGs were computer-analyzed and then manually over read and coded using the Minnesota code criteria [11] by a single cardiologist (S.Q.) to improve diagnostic accuracy. Left ventricular hypertrophy (LVH) was evaluated using both the Sokolow-Lyon and the Cornell criteria [12,13]. The QT interval was corrected for HR using the Bazett's formula using a standard HR of $60 \mathrm{bpm}$. Prolonged QTc interval was defined as $\mathrm{QTc} \geq 460 \mathrm{~ms}$. Abnormal Q/QS waves were defined as $\mathrm{Q}$ waves lasting greater than 0.04 seconds and greater than $1 \mathrm{~mm}$ in depth (code 1-1-2). ST and T wave abnormalities suggestive of ischemia were defined as horizontal or downsloping ST segments with or without $\mathrm{T}$ wave inversion (code 4-1-2). Ischemic $\mathrm{T}$ wave changes were defined as symmetric or deeply inverted $\mathrm{T}$ waves or biphasic $\mathrm{T}$ waves (codes 5-2). Ischemic EKG abnormalities were then defined as the presence of ST and T wave abnormalities suggestive of ischemia, ischemic $\mathrm{T}$ wave changes, abnormal Q/QS waves, and the presence of left bundle branch block (code 7-1-1).

\subsection{Statistical Analysis}

Data are summarized as mean and standard deviation for parametric data, or median and interquartile range (IQR) for nonparametric data. Participant demographics were stratified by gender and evaluated using univariate analysis. Student's t-test was used to compare groups for continuous parametric data, the Kruskall Wallis Test for continuous nonparametric data, and the Chi Square Test Statistic for categorical data. Multiple linear regression analysis and logistic regression analysis, for continuous and categorical data respectively, and Pearson Product Moment Correlation, were used to evaluate associations between variables. QTc intervals and HR were divided into quartiles and analyzed as categorical variables. A p value $<0.05$ was considered significant. All analyses were performed using SAS 9.2 TS level 1MO (SAS Institute Inc., Cary, NC).

\section{RESULTS}

\subsection{Cohort Profile}

Participant demographics are listed in Table 1. The median age was 43 years (range 18 - 93 years); 67.5\% $(\mathrm{n}=$ $865)$ were female. There was a high prevalence of coronary risk factors in this cohort. Approximately one in four subjects was hypertensive $(23.4 \%)$, diabetic $(28.8 \%)$, or a smoker $(27.5 \%)$. Women were more likely to be hypertensive $(\mathrm{p}<0.01)$, with no gender difference regarding prevalence of diabetes. However, fasting glucose levels were higher among men $(p<0.001)$. Mean SBP and mean DBP were also higher among men $(\mathrm{p}<0.001)$, 
Table 1. Cohort demographics. Cameron County Hispanic Cohort $(\mathrm{n}=1280)$, is a homogenous community-dwelling Mexican American cohort living in Brownsville (Cameron County), Texas.

\begin{tabular}{|c|c|c|c|c|}
\hline & Total $(n=1280)$ & Male $(n=415)$ & Female $(n=865)$ & P value (Males vs. Females) \\
\hline Continuous Variable & Median (IQR) ${ }^{\mathrm{a}}$ & Median (IQR) ${ }^{\mathrm{a}}$ & Median $(I Q R)^{a}$ & \\
\hline Age (years) & $43(24)$ & $43(23)$ & $42(23)$ & 0.25 \\
\hline Mean $\mathrm{SBP}^{\mathrm{b}}(\mathrm{mmHg})$ & $113(20)$ & $115(16)$ & $113(21)$ & 0.0003 \\
\hline Mean $\mathrm{DBP}^{\mathrm{c}}(\mathrm{mmHg})$ & $71(12)$ & $75(12)$ & $69(12)$ & $<0.0001$ \\
\hline Fasting Glucose (mg/dL) & $97(16)$ & $99(16)$ & $96(16)$ & $<0.0001$ \\
\hline $\mathrm{HbA} 1 \mathrm{c}^{\mathrm{d}}$ & $5.6(1.4)$ & $5.6(1.3)$ & $5.6(1.4)$ & 0.40 \\
\hline Total Cholesterol (mg/dL) & $183(55)$ & $185.5(59)$ & $181(54)$ & 0.06 \\
\hline Triglyceride (mg/dL) & $128(107.5)$ & $145(134)$ & $120(97)$ & $<0.0001$ \\
\hline $\mathrm{HDL}^{\mathrm{e}}$-Cholesterol (mg/dL) & $46(14)$ & $42(12)$ & $47(14)$ & $<0.0001$ \\
\hline LDL-Cholesterol (mg/dL) & $107(42)$ & $111(45.2)$ & $105.2(39.4)$ & 0.04 \\
\hline$C R P^{g}(\mathrm{mg} / \mathrm{dL})$ & $2.9(3.2)$ & $2.4(2.5)$ & $3.2(3.3)$ & $<0.0001$ \\
\hline $\mathrm{BMI}^{\mathrm{h}}$ & $30(7.7)$ & $29.6(6.7)$ & $30.2(8)$ & 0.07 \\
\hline Waist Circumference (cm) & $99.3(17.3)$ & $102(15.6)$ & $98(17.7)$ & $<0.0001$ \\
\hline Median Income (US dollars) & $14,400(14,349)$ & $19,519(18,000)$ & $12876(13200)$ & $<0.0001$ \\
\hline Years of Education & $10(6)$ & $12(5)$ & $9(6)$ & 0.002 \\
\hline Categorical Variable & n (\%) & n (\%) & n (\%) & \\
\hline Diabetic & $368(28.8)$ & $121(29.2)$ & $247(28.6)$ & 0.82 \\
\hline Hypertensive & $299(23.4)$ & $77(18.6)$ & $222(25.7)$ & 0.005 \\
\hline Metabolic Syndrome & $552(43.4)$ & $163(39.4)$ & $389(45.4)$ & 0.04 \\
\hline Obese $\left(\mathrm{BMI}^{\mathrm{h}} \geq 30\right)$ & $649(50.7)$ & $193(46.5)$ & $456(52.7)$ & 0.04 \\
\hline Morbidly Obese $\left(\mathrm{BMI}^{\mathrm{h}} \geq 40\right)$ & $98(7.6)$ & $22(5.3)$ & $76(8.8)$ & 0.03 \\
\hline Smoker & $352(27.5)$ & $211(50.8)$ & $141(16.3)$ & $<0.0001$ \\
\hline Employed & $653(51.0)$ & $305(73.5)$ & $348(40.2)$ & $<0.0001$ \\
\hline
\end{tabular}

${ }^{\mathrm{a}} \mathrm{IQR}=$ Interquartile Range; ${ }^{\mathrm{b}} \mathrm{SBP}=$ Systolic Blood Pressure; ${ }^{\mathrm{C}} \mathrm{DBP}=$ Diastolic Blood Pressure; ${ }^{\mathrm{d}} \mathrm{HbA1c}=$ Hemoglobin A1c; ${ }^{\mathrm{e}} \mathrm{HDL}=$ High Density Cholesterol; ${ }^{\mathrm{f}} \mathrm{LDL}=$ Low Density Cholesterol; ${ }^{\mathrm{g}} \mathrm{CRP}=\mathrm{C}$-Reactive Protein; ${ }^{\mathrm{h}} \mathrm{BMI}=$ Body Mass Index.

suggestive of poorer BP and diabetes control among men. There was a very high prevalence of smoking among the male subjects, with one in two Mexican American males categorized as a smoker $(50.8 \%$ versus $16.3 \%$; $p<0.001)$.

On the other hand, there was a higher prevalence of obesity among women compared to men $(52.7 \%$ versus $46.5 \% ; \mathrm{p}=0.04)$ with more women classified as morbidly obese $(8.8 \%)$ compared to men $(5.3 \%)(p=0.03)$. In general, the majority (82.9\%) of this cohort was either overweight or obese, with a median cohort BMI of 30 (IQR 7.7); 7.6\% were morbidly obese. Nearly one in two persons met criteria for the metabolic syndrome (43.4\%), with a higher prevalence in women $(45.4 \%)$ than in men $(39.4 \%)(\mathrm{p}=0.04)$.

The mean CRP was $(3.6 \pm 2.4) \mathrm{mg} / \mathrm{L}$, which is considered to be in the high risk category for cardiovascular events [9]. Women had significantly higher levels of CRP compared to men $((3.9 \pm 2.4) \mathrm{mg} / \mathrm{L}$ versus $((3.1 \pm$ 2.3) $\mathrm{mg} / \mathrm{L} ; \mathrm{p}<0.001)$. Using multiple linear regression analy- sis, hypertension, diabetes, metabolic syndrome, obesity, BMI, waist circumference, and HDL-Chol were significantly associated with CRP levels after adjusting for age and gender $(p<0.01)$.

\subsection{EKG Findings}

Most subjects were in normal sinus rhythm with one subject in ectopic atrial rhythm and three subjects in atrial fibrillation (prevalence of $0.2 \%$ ). The prevalence of LVH was $3.6 \%$. After controlling for age and gender, the presence of LVH was significantly associated with hypertension, metabolic syndrome, waist circumference, and BMI $(p<0.05)$. The prevalence of an interventricular conduction delay was $3.5 \%(\mathrm{n}=45)$ with the majority having either a nonspecific interventricular conduction delay $(n=17)$ or a right bundle branch block $(n=10)$. Two subjects had a left bundle branch block. Ectopic beats were seen in $1.6 \%(\mathrm{n}=20)$ of the cohort, with the majority being isolated premature atrial complexes.

Abnormal Q waves were seen in $1.4 \%(n=18)$ of the 
cohort. After adjusting for other covariates, age and LDLChol were significantly associated with the presence of an abnormal Q wave on a resting EKG $(\mathrm{p}<0.05)$. Ischemic EKG abnormalities were seen in $12.7 \%(n=163)$ of the cohort. Using multivariate regression analysis, ischemic EKG abnormalities were more prevalent in older subjects, in persons with hypertension, diabetes, and the metabolic syndrome, and in those who were obese (Table 2). Ischemic EKG abnormalities were also more prevalent in subjects with higher SBP and DBP, higher total cholesterol, larger waist circumferences, and higher BMI $(\mathrm{p}<0.01)$.

The mean cohort QTc interval was $(408.4 \pm 25.7) \mathrm{ms}$ while the mean cohort HR was $(66.4 \pm 8.6) \mathrm{bpm}$. Only $1.3 \%$ of the cohort had prolonged QTc interval $(>460 \mathrm{~ms})$ and only $0.7 \%$ had a resting $\mathrm{HR} \geq 90 \mathrm{bpm}$ (maximum mean resting HR was $100 \mathrm{bpm}$ ). Women had longer QTc intervals $(412.5 \pm 23.8) \mathrm{ms}$ versus $(400.1 \pm 27.3) \mathrm{ms} ; \mathrm{p}<$ $0.001)$ and higher mean $\mathrm{HR}(66.9 \pm 8.4 \mathrm{bpm}$ versus $(65.3$ $\pm 8.9)$ bpm; $\mathrm{p}<0.01)$ compared to men. After adjusting for age and gender, subjects in the highest quartiles of QTc interval were more likely to have hypertension obesity, the metabolic syndrome, and had higher BMI, higher HbA1c, larger waist circumference, and higher CRP levels $(\mathrm{p}<0.01)$ (Table 3). Similarly, after controlling for age and gender, subjects with the highest quartiles of mean HR were more likely to have diabetes, obesity, the metabolic syndrome, and had higher BMI, higher fasting glucose and HbAlc, higher triglyceride levels, larger waist circumferences, and higher CRP levels $(p<0.01)$

(Table 4).

\section{DISCUSSION}

This study describes the prevalent EKG abnormalities in a homogenous community-dwelling Mexican American cohort. The main finding in this study is that persons with hypertension, diabetes, obesity, and the metabolic syndrome were more likely to have ischemic electrocardiographic abnormalities, longer QTc intervals, and higher resting heart rates on a resting EKG. Studies reporting EKG abnormalities among Hispanics are scarce $[14,15]$ and most reference data have been collected in Caucasian populations. This study contributes to the body of

Table 2. Ischemic electrocardiographic abnormalities and coronary risk factors. Ischemic electrocardiographic abnormalities were defined as the presence of ST and T wave abnormalities suggestive of ischemia, ischemic $\mathrm{T}$ wave changes, abnormal Q/QS waves, and the presence of left bundle branch block.

\begin{tabular}{|c|c|c|c|c|}
\hline & Ischemic EKG ${ }^{\mathrm{a}}(\mathrm{n}=163)$ & No Ischemic EKG ${ }^{\text {a }}$ Abnormalities $(n=1117)$ & P Value & $\mathrm{OR}^{\mathrm{b}}(95 \% \mathrm{CI})$ \\
\hline Continuous Variable & Median (IQR) ${ }^{\mathrm{c}}$ & Median (IQR) ${ }^{\mathrm{c}}$ & & \\
\hline Age (Years) & $55(19)$ & $41(23)$ & $<0.001$ & $1.05(1.04,1.07)$ \\
\hline Mean SBP ${ }^{d}$ & $123(27)$ & $113(18)$ & $<0.001$ & $1.03(1.02,1.04)$ \\
\hline Mean $\mathrm{DBP}^{\mathrm{e}}$ & $75(13)$ & $70(12)$ & $<0.001$ & $1.03(1.02,1.05)$ \\
\hline Fasting Glucose (mg/dL) & $103(26)$ & $97(16)$ & $<0.001$ & $1.003(1.000,1.006)$ \\
\hline $\mathrm{HbA} 1 \mathrm{c}^{\mathrm{f}}$ & $5.9(1.5)$ & $5.6(1.3)$ & $<0.001$ & $1.08(1.00,1.16)$ \\
\hline Total Cholesterol (mg/dL) & $193.5(58)$ & $182(54)$ & $<0.01$ & $1.007(1.003,1.01)$ \\
\hline Triglyceride (mg/dL) & $161.5(124)$ & $124(104)$ & $<0.001$ & $1.001(1.000,1.002)$ \\
\hline $\mathrm{HDL}^{\mathrm{g}}$-Cholesterol (mg/dL) & $46(11)$ & $46(15)$ & 0.66 & $1.003(0.989,1.016)$ \\
\hline $\mathrm{LDL}^{\mathrm{h}}$-Cholesterol (mg/dL) & $117.6(43.6)$ & $106(42)$ & 0.04 & $1.004(0.999,1.008)$ \\
\hline $\mathrm{CRP}^{\mathrm{i}}(\mathrm{mg} / \mathrm{L})$ & $3.1(3.4)$ & $2.9(3.1)$ & 0.36 & $1.03(0.96,1.12)$ \\
\hline$B M \mathrm{I}^{\mathrm{j}}$ & $30.9(6.4)$ & $29.9(7.8)$ & $<0.01$ & $1.03(1.01,1.05)$ \\
\hline Waist Circumference (cm) & $104(15.5)$ & $99(17.1)$ & $<0.001$ & $1.02(1.01,1.03)$ \\
\hline Categorical Variable & n (\%) & n (\%) & & \\
\hline Females & $113(68.7)$ & $752(67.32)$ & 0.61 & $1.10(0.75,1.57)$ \\
\hline Diabetic & $68(41.72)$ & $300(26.86)$ & $<0.001$ & $1.95(1.39,2.73)$ \\
\hline Hypertensive & $70(42.94)$ & $229(20.50)$ & $<0.001$ & $2.92(2.07,4.11)$ \\
\hline Metabolic Syndrome & $99(60.74)$ & $453(40.88)$ & $<0.001$ & $2.24(1.60,3.13)$ \\
\hline Obese $\left(\mathrm{BMI}^{\mathrm{j}} \geq 30\right)$ & $98(60.12)$ & $551(49.33)$ & 0.01 & $1.55(1.11,2.16)$ \\
\hline Smoker & $50(30.67)$ & $302(27.04)$ & 0.33 & $1.19(0.84,1.71)$ \\
\hline
\end{tabular}

${ }^{\mathrm{a}} \mathrm{EKG}=$ Electrocardiogram; ${ }^{\mathrm{b}} \mathrm{OR}=$ Odds Ratio; ${ }^{\mathrm{c}} \mathrm{IQR}=$ Interquartile Range; ${ }^{\mathrm{d}} \mathrm{SBP}=$ Systolic Blood Pressure; ${ }^{\mathrm{e}} \mathrm{DBP}=\mathrm{Diastolic}$ Blood Pressure; ${ }^{\mathrm{f}} \mathrm{Hb} \mathrm{A} 1 \mathrm{c}=$ Hemoglobin A1c; ${ }^{g} \mathrm{HDL}=$ High Density Cholesterol; ${ }^{\mathrm{h}} \mathrm{LDL}=$ Low Density Cholesterol; ${ }^{\mathrm{i}} \mathrm{CRP}=\mathrm{C}-$ Reactive Protein; ${ }^{\mathrm{j}} \mathrm{BMI}=\mathrm{Body}$ Mass Index. 
Table 3. QTc intervals obtained from the resting electrocardiogram, divided into quartiles. P values are adjusted for age and gender.

\begin{tabular}{|c|c|c|c|c|c|}
\hline QTe Interval & $\begin{array}{c}\text { QTe1 } \\
\leq 395 \mathrm{~ms}\end{array}$ & $\begin{array}{c}\text { QTc2 } \\
>\mathbf{3 9 5}-\leq \mathbf{4 0 9} \mathrm{ms}\end{array}$ & $\begin{array}{c}\text { QTe3 } \\
>409-\leq 422 \mathrm{~ms}\end{array}$ & $\begin{array}{c}\text { QTe4 } \\
>422 \mathrm{~ms}\end{array}$ & $\begin{array}{c}\text { P Value } \\
\text { (QTc4 vs. QTc1) }\end{array}$ \\
\hline Continuous Variable & Median $(I Q R)^{a}$ & Median $(I Q R)^{a}$ & Median $(I Q R)^{a}$ & Median $(I Q R)^{a}$ & \\
\hline Mean SBP ${ }^{b}$ & $112(17)$ & $112.5(2-0)$ & $115(19)$ & $117(24)$ & $<0.001$ \\
\hline Mean $\mathrm{DBP}^{\mathrm{c}}$ & $71(12)$ & $71(13)$ & $71(12)$ & $71(13)$ & 0.82 \\
\hline Fasting Glucose (mg/dL) & $96(13)$ & $97(16.5)$ & $99(17)$ & $100(22)$ & $<0.01$ \\
\hline $\mathrm{HbA} 1 \mathrm{c}^{\mathrm{d}}$ & $5.4(1.1)$ & $5.6(1.2)$ & $5.6(1.5)$ & $5.8(1.4)$ & $<0.01$ \\
\hline $\mathrm{CRP}^{\mathrm{e}}(\leq 10 \mathrm{mg} / \mathrm{L})$ & $2.5(2.5)$ & $3(3.5)$ & $3.1(3.3)$ & $3.2(3.1)$ & $<0.001$ \\
\hline $\mathrm{BMI}^{\mathrm{f}}$ & $28.5(6.8)$ & $30(8.3)$ & $30.4(7.9)$ & $31(7.4)$ & $<0.001$ \\
\hline Waist Circumference (cm) & $97.1(17)$ & $98(18.9)$ & $100(15.3)$ & $10.25(17.1)$ & $<0.001$ \\
\hline Categorical Variable & $n(\%)$ & $n(\%)$ & $n(\%)$ & $n(\%)$ & \\
\hline Diabetic & $75(23.4)$ & $84(25.9)$ & $106(31.4)$ & $103(34.7)$ & $<0.01$ \\
\hline Hypertensive & $49(15.3)$ & $63(19.4)$ & $76(22.5)$ & $111(37.4)$ & $<0.001$ \\
\hline Metabolic Syndrome & $98(30.8)$ & $130(40.8)$ & $171(50.7)$ & $153(51.5)$ & $<0.001$ \\
\hline Obese $\left(\mathrm{BMI}^{\mathrm{f}} \geq 30\right)$ & $131(40.8)$ & $162(50.0)$ & $182(53.9)$ & $174(58.6)$ & $<0.001$ \\
\hline Smoker & $105(32.7)$ & $88(27.2)$ & $78(23.1)$ & $81(27.3)$ & 0.14 \\
\hline
\end{tabular}

${ }^{\mathrm{a}} \mathrm{IQR}=$ Interquartile Range; ${ }^{\mathrm{b}} \mathrm{SBP}=$ Systolic Blood Pressure; ${ }^{\mathrm{c}} \mathrm{DBP}=$ Diastolic Blood Pressure; ${ }^{\mathrm{d}} \mathrm{HbA} 1 \mathrm{c}=$ Hemoglobin A1c; ${ }^{\mathrm{e}} \mathrm{CRP}=\mathrm{C}-\mathrm{Reactive} \mathrm{Protein} ;{ }^{\mathrm{f}} \mathrm{BMI}$ $=$ Body Mass Index.

Table 4. Mean heart rates obtained from the resting electrocardiogram, divided into quartiles. P values are adjusted for age and gender.

\begin{tabular}{|c|c|c|c|c|c|}
\hline Mean $H^{g}$ & $\begin{array}{l}\text { Mean } \mathrm{HR}^{\mathrm{g}} 1 \\
\leq 60.5 \mathrm{bpm}\end{array}$ & $\begin{array}{c}\text { Mean HR }{ }^{\mathrm{g}} 2 \\
>\mathbf{6 0 . 5}-\leq 65.5 \mathrm{bpm}\end{array}$ & $\begin{array}{c}\text { Mean } \mathrm{HR}^{\mathrm{g} 3} \\
>\mathbf{6 5 . 5}-\leq 72 \mathrm{bpm}\end{array}$ & $\begin{array}{c}\text { Mean } \mathrm{HR}^{\mathrm{g}} 4 \\
>72 \mathrm{bpm}\end{array}$ & P Value Mean $H^{g}{ }^{9}$ vs. Mean $H^{g}{ }^{g}$ \\
\hline Continuous Variable & Median $(I Q R)^{a}$ & Median $(I Q R)^{a}$ & Median $(I Q R)^{a}$ & Median $(I Q R)^{a}$ & \\
\hline Mean SBP ${ }^{b}$ & $114(22)$ & $113(19)$ & $113(17)$ & $115(21)$ & 0.23 \\
\hline Mean DBP ${ }^{c}$ & $69(12)$ & $71(12)$ & $71(14)$ & $73(13)$ & $<0.001$ \\
\hline Fasting Glucose (mg/dL) & $97(14)$ & $97(15)$ & $96(17)$ & $100(29)$ & $<0.01$ \\
\hline $\mathrm{HbA} 1 \mathrm{c}^{\mathrm{d}}$ & $5.5(1.1)$ & $5.6(1.2)$ & $5.6(1.4)$ & $5.9(1.8)$ & $<0.001$ \\
\hline Triglyceride (mg/dL) & $120.5(100)$ & $126.5(99)$ & $129(112)$ & $138(112)$ & $<0.01$ \\
\hline $\mathrm{CRP}^{\mathrm{e}}(\leq 10 \mathrm{mg} / \mathrm{L})$ & $2.7(2.7)$ & $2.8(3.1)$ & $3.1(3.1)$ & $3.4(3.7)$ & $<0.01$ \\
\hline $\mathrm{BMI}^{\mathrm{f}}$ & $28.7(7.1)$ & $30.2(7.4)$ & $29.9(7.2)$ & $31.4(9.1)$ & $<0.001$ \\
\hline Waist Circumference $(\mathrm{cm})$ & $97.8(16.8)$ & $98.9(16.2)$ & $99.1(16.3)$ & $102.2(20.3)$ & $<0.001$ \\
\hline Categorical Variable & $n(\%)$ & $n(\%)$ & $n(\%)$ & $n(\%)$ & \\
\hline Diabetic & $75(21.9)$ & $87(27.6)$ & $95(29.3)$ & $111(37.1)$ & $<0.001$ \\
\hline Hypertensive & $76(22.2)$ & $70(22.2)$ & $67(20.7)$ & $86(28.8)$ & 0.07 \\
\hline Metabolic Syndrome & $118(34.6)$ & $119(37.8)$ & $159(49.5)$ & $156(53.1)$ & $<0.001$ \\
\hline Obese $\left(\mathrm{BMI}^{\mathrm{f}} \geq 30\right)$ & $145(42.4)$ & $165(52.4)$ & $160(49.4)$ & $179(59.9)$ & $<0.001$ \\
\hline Smoker & $110(32.2)$ & $88(27.9)$ & $75(23.2)$ & $79(26.4)$ & 0.12 \\
\hline
\end{tabular}

${ }^{\mathrm{a}} \mathrm{IQR}=$ Interquartile Range; ${ }^{\mathrm{b}} \mathrm{SBP}=$ Systolic Blood Pressure; ${ }^{\mathrm{c}} \mathrm{DBP}=$ Diastolic Blood Pressure; ${ }^{\mathrm{d}} \mathrm{HbA} 1 \mathrm{c}=$ Hemoglobin A1c; ${ }^{\mathrm{e}} \mathrm{CRP}=\mathrm{C}-\mathrm{Reactive}$ Protein; ${ }^{\mathrm{f}} \mathrm{BMI}$ $=$ Body Mass Index; ${ }^{\mathrm{g}} \mathrm{HR}=$ Heart Rate.

literature on EKG abnormalities in this large US minority population.

Resting ischemic EKG abnormalities were more prevalent among subjects with hypertension, diabetes, obe- sity, and the metabolic syndrome. Our findings are consistent with published literature showing similar associations in other ethnic groups [16-18]; however, to our knowledge, this study is one of few reports on these as- 
sociations in a Mexican American community-dwelling cohort. The reported prevalence in our study is similar to that seen in other community-based studies such as the Persian Gulf Healthy Heart Project [16], as well as aggregate data from four large Belgian epidemiologic studies [17], although it appears to be higher than that reported for Koreans [18].

Autonomic dysfunction has been implicated in sudden cardiac death and is a marker of increased cardiovascular mortality in persons with and without known cardiovascular disease $[2,3]$. Recently, several studies have described associations of QTc interval and resting HR with diabetes, obesity, and the metabolic syndrome in other ethnic groups $[4,5,19,20]$. Our study is consistent with the published literature but to our knowledge, is the first to describe these associations among Mexican Americans. Sympathetic overactivity or sympathetic imbalance seems to underlie several of the components of obesity, diabetes, and the metabolic syndrome [21]. The finding of a strong association between parameters suggestive of an abnormal autonomic tone and this "dysmetabolic" state provides support for shared pathophysiologic mechanisms to explain increased cardiovascular mortality in these patients. A strong and consistent association between autonomic neuropathy and increased risk of mortality has been shown in diabetics [22]. It has been suggested that a baseline determination of autonomic function be performed in all patients with diabetes mellitus [22]. We would argue that a similar assessment of autonomic tone be performed for obese patients and patients with the metabolic syndrome. The presence of these markers of autonomic dysfunction should then alert a healthcare professional to further risk stratification or an intensification of appropriate therapies to potentially modulate autonomic function and attenuate this risk. Whether these findings translate to increased cardiovascular mortality risk in this cohort remains to be seen.

The other important finding in the study is the very high prevalence of coronary risk factors in this cohort, consistent with what has been previously described among Mexican Americans [23]. In particular, nearly one in two persons met criteria for the metabolic syndrome, and only $17 \%$ of the entire cohort had a normal BMI. The prevalence of metabolic syndrome in this homogenous Mexican American cohort (43.4\%) is higher than that reported for the general American population in the National Health and Nutrition Examination Survey (NHANES) Survey and the Women's Health Study (23.4\% and 24.4\%, respectively) [24]. Similarly, the prevalence of obesity (50.7\%), and overweight and obesity combined (82.9\%) in this cohort is much higher than the most recent prevalence estimates for these conditions in the US population (33.8\% and $68.0 \%$, respectively) [25].

Our study had some factors that may influence the re- sults. This study is a cross-sectional study and we have no follow-up data to evaluate the implications of our findings on cardiovascular events and outcomes. Longitudinal data are being collected and follow-up EKGs will be analyzed to evaluate changes over time. The $\mathrm{CCHC}$ is a homogenous Mexican American cohort and hence, we do not have a comparison cohort. However, the findings in this study can be placed in context with the published literature regarding other ethnic groups and the general US population. A strength of this study though, is the very homogeneity of the cohort, as the US Hispanic population as a whole is actually an ethnically diverse group with varying risk profiles. We also opted to use simple EKG parameters, rather than complex computergenerated factors, because the parameters chosen are easily defined and interpreted by clinicians, with wider clinical applicability.

In summary, in this community-dwelling Mexican American cohort, persons with diabetes, hypertension, the metabolic syndrome, and obesity were more likely to have ischemic EKG changes, longer QTc intervals, and higher resting HR. The resting EKG is a simple, low-cost, and widely available cardiovascular diagnostic test which can provide a wealth of information related to coronary risk factors, as described in this study. Evaluation of latent cardiovascular disease in this high risk population would be advantageous as it may prompt clinicians to further risk stratification and/or earlier institution or intensification of appropriate therapies. Hence, a resting EKG can play a complementary role in the comprehensive evaluation of cardiovascular risk among Mexican Americans.

\section{ACKNOWLEDGEMENTS}

This work was supported by MD000170 P20 funded from the National Institute on Minority Health and Disparities, and the Centers for Translational Science Award UL1 RR024018-05 from the National Center for Research Resources.

We thank our cohort recruitment team, particularly, Elizabeth Braunstein, Julie Ramirez, Jody Rodriguez, and Rocio Uribe. We also thank Marcela Montemayor and other laboratory staff for their contributions, and Christina Villarreal for administrative support. We thank Valley Baptist Medical Center, Brownsville, Texas for providing us space for our Center for Clinical and Translational Science Clinical Research Unit. We also thank the community of Brownsville and the participants who so willingly participated in this study in their city.

\section{REFERENCES}

[1] De Bacquer, D., De Backer, G., Kornitzer, M. and Blackburn, H. (1998) Prognostic value of ECG findings for total, cardiovascular disease, and coronary heart disease death in men and women. Heart, 80, 570-577.

[2] Schouten, E.G., Dekker, J.M., Meppelink, P., Kok, F.J., 
Vandenbroucke, J.P. and Pool, J. (1991) QT interval prolongation predicts cardiovascular mortality in an apparently healthy population. Circulation, 84, 1516-1523.

[3] Cooney, M.T., Vartiainen, E., Laakitainen, T., Juolevi, A., Dudina, A. and Graham, I.M. (2010) Elevated resting heart rate is an independent risk factor for cardiovascular disease in healthy men and women. American Heart Journal, 159, 612-619. doi:10.1016/j.ahj.2009.12.029

[4] Rana, J.S., Hardison, R.M., Pop-Busui, R., Brooks, M.M., Jones, T.L., Nesto, R.W., et al. (2010) Resting heart rate and metabolic syndrome in patients with diabetes and coronary artery disease in bypass angioplasty revascularization investigation 2 diabetes (BARI 2D) Trial. Preventive Cardiology, 13, 112-116. doi:10.1111/j.1751-7141.2010.00067.x

[5] Faramawi, M.F., Wildman, R.P., Gustat, J., Rice, J. and Kareem M.Y.A. (2008) The association of the metabolic syndrome with QTc interval in NHANES III. European Journal of Epidemiology, 23, 459-465. doi:10.1007/s10654-008-9252-4

[6] Meigs, J.B., Wilson, P.W.F., Nathan, D.M., D’Agostino, R.B., Williams, K. and Haffner, S.M. (2003) Prevalence and characteristics of the metabolic syndrome in the San Antonio Heart and Framingham Offspring Studies. Diabetes, 52, 2160-2167.

[7] Bernstein, R. (2008) US Hispanic population surpassed 45 million: Now 15 percent of total US.

http://www.census.gov/newsroom/releases/archives/popu lation/cb08-67.html

[8] Fisher-Hoch, S.P., Rentfro, A.R., Salinas, J.J., Perez, A., Brown, H.S., Reininger, B.M., et al. (2010) Socioeconomic status and prevalence of obesity and diabetes in a Mexican American community, Cameron County, Texas, 2004-2007. Preventing Chronic Disease, 7, 1-10.

[9] Pearson, T.A., Mensah, G.A., Alexander, W., Anderson, J.L., Cannon, R.O., Criqui, M., et al. (2003) Markers of inflammation and cardiovascular disease: Application to clinical and public health practice: A statement for healthcare professionals from the Centers for Disease Control and Prevention and the American Heart Association. Circulation, 107, 499-511. doi:10.1161/01.CIR.0000052939.59093.45

[10] Executive Summary (2010) Standards of medical care in diabetes-2010. Diabetes Care, 33, S4-S10. doi:10.2337/dc10-S004

[11] Prineas, R., Crow, R. and Blackburn, H. (1982) The Minnesota code manual of electrocardiographic findings. John Wright-PSG Inc., Littleton.

[12] Sokolow, M. and Lyon, T.O. (1949) The ventricular complex in left ventricular hypertrophy as obtained by unipolar precordial and link leads. American Heart Journal, 37, 161-186. doi:10.1016/0002-8703(49)90562-1

[13] Casale, P.N., Devereux, R.B., Alonso, D.R., Campo, E. and Kligfield, P. (1987) Improved sex-specific criteria of left ventricular hypertrophy for clinical and computer interpretation of electrocardiograms: Validation with autopsy findings. Circulation, 75, 565-572.

doi:10.1161/01.CIR.75.3.565
[14] Mitchell, B.D., Hazuda, H.P., Haffner, S.M., Patterson, J.K. and Stern, M.P. (1991) Myocardial infarction in Mexican-Americans and non-hispanic whites: The San Antonio heart study. Circulation, 83, 45-51.

[15] Perez, M.V., Yaw, T.S., Myers, J. and Froelicher, V.F. (2007) Prognostic value of the computerized ECG in Hispanics. Clinical Cardiology, 30, 189-194. doi: $10.1002 /$ clc. 20053

[16] Nabipour, I., Amiri, M., Imami, S.R., Jahfari, S.M., Shafeiae, E., Nosrati, A., et al. (2007) The metabolic syndrome and nonfatal ischemic heart disease: A population based study. International Journal of Cardiology, 118, 48-53. doi:10.1016/j.ijcard.2006.06.017

[17] De Bacquer, D., De Backer, G. and Kornitzer, M. (2000) Prevalences of ECG findings in large population based samples of men and women. Heart, 84, 625-633. doi:10.1136/heart.84.6.625

[18] Kim, H.K., Kim, C.H., Ko, K.H., Park, S.W., Park, J.Y. and Lee, K.U. (2010) Variable association between components of the metabolic syndrome and electrocardiographic abnormalities in Korean adults. Korean Journal of Internal Medicine, 25, 174-180. doi:10.3904/kjim.2010.25.2.174

[19] Peng, S., Yu, Y., Hao, K., Xing, H., Li, D., Chen, C., et al. (2006) Heart rate-corrected QT interval duration is significantly associated with blood pressure in Chinese hypertensives. Journal of Electrocardiology, 39, 206-210. doi:10.1016/j.jelectrocard.2005.08.007

[20] Fraley, M.A., Birchem, J.A., Senkottaiyan, N. and Alpert, M.A. (2005) Obesity and the electrocardiogram. Obesity Reviews, 6, 275-281. doi:10.1111/j.1467-789X.2005.00199.x

[21] Grassi, G., Arenare, F., Quarti-Trevano, F., Seravalle, G. and Mancia, G. (2009) Heart rate, sympathetic cardiovascular influences, and the metabolic syndrome. Progress in Cardiovascular Diseases, 52, 31-37. doi:10.1016/j.pcad.2009.05.007

[22] Maser, R.E., Mitchell, B.D., Vink, A.I. and Freeman, R. (2003) The association between cardiovascular autonomic neuropathy and mortality in individuals with diabetes. Diabetes Care, 26, 1895-1901. doi:10.2337/diacare.26.6.1895

[23] Wei, M., Mitchell, B.D., Haffner, S.M. and Stern, M.P. (1996) Effects of cigarette smoking, diabetes, high cholesterol, and hypertension on all-cause mortality and cardiovascular disease mortality in Mexican Americans. American Journal of Epidemiology, 144, 1058-1065.

[24] Ridker, P.M., Buring, J.E., Cook, N.R. and Rifai, N. (2003) C-reactive protein, the metabolic syndrome, and risk of incident cardiovascular events: An 8-year followup of 14,719 initially healthy American women. Circulation, 107, 391-397. doi:10.1161/01.CIR.0000055014.62083.05

[25] Flegal, K.M., Carroll, M.D., Ogden, C.L. and Curtin, L.R. (2010) Prevalence and trends in obesity among US adults, 1999-2008. Journal of the American Medical Association, 303, 235-241. doi:10.1001/jama.2009.2014 